\title{
The association of potassium intake with bone mineral density and the prevalence of osteoporosis among older Korean adults
}

\author{
Jinwoo $\mathrm{Ha}^{1}$, Seong-Ah Kim 1 , Kyungjoon $\mathrm{Lim}^{2}$ and Sangah Shin ${ }^{15}$ \\ ${ }^{1}$ Department of Food and Nutrition, Chung-Ang University, Gyeonggi-do 17546, Korea \\ ${ }^{2}$ Department of Physiology, Anatomy \& Microbiology, La Trobe University, Melbourne, 3086, Australia
}

BACKGROUND/OBJECTIVES: Osteoporosis is characterized by low bone mass and results in vulnerability to fracture. Calcium and vitamin D are known to play an important role in bone health. Recently, potassium has been identified as another important factor in skeletal health. We examined the link between potassium intake and bone health among the Korean older adult population.

SUBJECTS/METHODS: This retrospective, cross-sectional study included 8,732 men and postmenopausal women over 50 years old who completed the Korean National Health and Nutrition Survey (KNHANES) between 2008 and 2011. Potassium consumption was evaluated using a 24-hour recall method. Bone mineral density (BMD) was measured at three sites (total hip, femur neck, and lumbar spine) by dual-energy X-ray absorptiometry (DEXA). Multinomial logistic regression was used to examine the link between potassium intake and prevalence of osteoporosis and osteopenia, after controlling for potential confounding variables. RESULTS: The BMD of the total femur and Ward's triangle were significantly different according to the potassium intake among men $(P=0.031$ and $P=0.010$, respectively). Women in the top tertile for potassium intake showed higher BMD than those in the bottom tertile at all measurement sites (all $P<0.05$ ). Daily potassium intake was significantly related to a decreased risk of osteoporosis at the lumbar spine in postmenopausal women (odds ratios: $0.68,95 \%$ confidence interval: $0.48-0.96, P$ trend $=0.031$ ). However, the dietary potassium level was not related to the risk of osteoporosis in men.

CONCLUSION: Current findings indicate that higher dietary potassium levels have a favorable effect on bone health and preventing osteoporosis in older Korean women.

Nutrition Research and Practice 2020;14(1):55-61; https://doi.org/10.4162/nrp.2020.14.1.55; pISSN 1976-1457 elSSN 2005-6168

Keywords: Osteoporosis, epidemiology, KNHANES, nutrition, population surveillance

\section{INTRODUCTION}

Osteoporosis is characterized by low bone mass and reduced bone structure, in which bone becomes brittle and fragile from loss of bone tissues, thus making it more vulnerable to fracture [1]. Osteoporosis is particularly associated with age and thus impose a heavy burden on global public health for aging population [2,3]. Among Korea, the prevalence of osteoporosis was $7.3 \%$ in male and $38.0 \%$ in female adults $\geq 50$ years old in 2011 and it has continuously increased [4]. This trend is thought to be a result of a westernized dietary lifestyle in Korea, along with demographic and sociological factors [5].

Diet is a crucial modifiable factor that causes or contributes to osteoporosis and fractures [6]. Even though diet play an important role in bone health, most studies has concentrated on single nutrients including calcium and vitamin $D$, or supplements containing these nutrients $[7,8]$. Recently, populationbased observational studies have been identified beneficial effects of dietary potassium and fruit and vegetables on bone health $[2,9,10]$. The most facilitated hypothesis regarding to benefit of dietary potassium on bone health is through its effect on acid-base balance, even though the role of the skeleton in $\mathrm{pH}$ regulation is controversial $[11,12]$. The western diet including high meats and cereal grains produces a low-grade metabolic acidosis [11]. The continual release of alkaline salts from bone for acid-base balance would cause bone loss and osteoporosis [13]. Fruit and vegetable intake could balance this excess acidity by providing alkaline salts of potassium [14]. Thus, the alkaline potassium salt is thought to prevent bone resorption for $\mathrm{pH}$ homeostasis [15]. In addition, increasing potassium intake increases urinary retention, reducing loss of calcium and thus creating a more positive calcium balance and inhibiting bone resorption $[16,17]$. The potassium bicarbonate, but not sodium bicarbonate, reduced urinary calcium excretion in healthy men [18], and the potassium citrate reduced urinary calcium excretion in men with uric acid nephrolithiasis [19]. It suggests that the positive effect of potassium could be through either suppressing calcium resorption or bone mineral dissolution or both [20].

Hence, the current study aimed to identify the link between dietary potassium and the prevalence of osteoporosis and

\footnotetext{
${ }^{\S}$ Corresponding Author: Sangah Shin, Tel. 82-31-670-3259, Fax. 82-31-675-1381, Email. ivory8320@cau.ac.kr

Received: April 29, 2019, Revised: May 28, 2019, Accepted: November 7, 2019

This is an Open Access article distributed under the terms of the Creative Commons Attribution Non-Commercial License (http://creativecommons.org/licenses/by-nc/3.0/) which permits unrestricted non-commercial use, distribution, and reproduction in any medium, provided the original work is properly cited.
} 
osteopenia in at-risk Koreans, using national survey data. We also analyzed the correlation of potassium intake with bone mineral density (BMD).

\section{SUBJECTS AND METHODS}

\section{Study design}

The KNHANES was conducted to investigate the health and nutritional status of Koreans from 1998 onwards. These were cross-sectional and nationally representative surveys performed by the Division of Chronic Disease Surveillance, and the Korea Centers for Disease Control and Prevention. The current study was based on data from the KNHANES IV-V (2008-2011), which conducted bone mineral density examinations. Data were collected from the cross-sectional KNHANES study database, including from health interviews, health examinations, and nutrition surveys, as well as BMD examinations.

A total of 21,303 participants were examined in KNHANES from 2008 to 2011. The International Society for Clinical Densitometry recommends that osteoporosis be diagnosed in postmenopausal women, and in men aged 50 and older, if the T-score of the lumbar spine, total hip or femoral neck is -2.5 or less [21]. According to this guideline, we selected postmenopausal women $(n=5,624)$ and men aged 50 years old and older ( $n=4,053$ ). Among 9,677 subjects, we additionally excluded subject $(n=5)$ without BMD data in current study. We defined postmenopausal status as not experiencing menstruation for $>12$ months, and included surgical menopause. An additional 940 participants with implausible energy intake based on dietary surveys $(<500$ or $>5,000 \mathrm{kcal} / \mathrm{d})$ were also excluded. Finally, the current study included 8,732 subjects (3,590 men and 5,142 women) for analysis.

The protocols for KNHANES IV-V were approved by the Institutional Review Board (IRB) of the Korea Centers for Disease Control and Prevention (2010-02CON21-C, 2011-02CON-06-C) and the research was performed in compliance with the guidelines laid down in the Declaration of Helsinki. Informed consent was obtained from all participants.

\section{Nutrition assessment}

Assessment of dietary consumption was conducted using a single-day 24-hour dietary recall method [22]. Highly qualified dietitians conducted a nutrition survey. Total energy and nutrient intake including protein, carbohydrate, fat, and calcium were estimated using the food composition table from the Korean National Rural Development Institute [23]. The residual method was applied to nutrient intake to adjust the total energy intake as demonstrated by Willett and Stampfer [24].

\section{$B M D$ measurement and definition of osteoporosis}

The BMD $\left(\mathrm{g} / \mathrm{cm}^{2}\right)$ was measured at the lumbar spine (L1-L4 spine) and five regions of the femur (total femur, trochanter, intertrochanter, femoral neck, and Ward's triangle) using dual-energy X-ray absorptiometry (DEXA, Discovery QDR 4500; Hologic, Inc., Waltham, MA, USA) at the health examination site. The BMD measurements were conducted via a standardized protocol from the International Society for Clinical Densitometry [21]. The BMD at the lumbar spine (L1-L4) and femoral neck were used for diagnosis of osteoporosis and osteopenia. We defined osteoporosis as a T-score $<-2.5$ and osteopenia as a T-score between -2.5 and -1.0; a T-score $>-1.0$ was considered normal bone mass [25].

\section{Covariates}

Physical examinations included body weight, height and body mass index (BMI) measurements. Demographic characteristics were obtained from a structured questionnaire. Educational levels were divided into four groups: $\leq$ elementary school, middle school, high school, and $\geq$ college. The household income was grouped into four levels by quartile. Lifestyle factors included smoking, alcohol drinking, and physical activity. Physical activity was estimated from the International Physical Activity Questionnaire (IPAQ) Korean version [26]. The minutes of Physical activity were then transformed into metabolic equivalents (METs) [27] and then we classified our subjects into 3 groups: "Health promoting active", "Minimally active" or "Inactive" in accordance with the IPAQ guidelines [28]. Serum 25-hydroxyvitamin D (25(OH)D) level was measured by a radioimmunoassay (DiaSorin Inc, Stillwater, MN, USA) using a gamma counter (1470 Wizard; PerkinElmer, Turku, Finland). Calcium intake was accessed by nutritional survey using 24 h-recall.

\section{Statistical analysis}

Categorical and continuous parameters were indicated as percentages and standard error, and as means and standard error, respectively. We applied the sampling weight value via the SAS survey procedure to consider the complex sampling design in all statistical analyses. Survey regression for comparisons of continuous variable and chi-square analysis for comparisons of categorical parameter were applied according to potassium intake categories.

To identify the association between dietary potassium intake and bone health, including osteoporosis, osteopenia, and BMD, we categorized subjects into tertile groups according to sex (men and women) and age (under 39, 40 to 49, 50 to 59, 60 to 69 and over 70) using proc rank analysis. The range of potassium intake for each tertile was as follows: for men, $386.7-2,726.5 \mathrm{mg} /$ day in T1, 1,994.6-3,950.9 mg/day in $\mathrm{T} 2$, and 2,935.6-18,573.0 mg/day in T3; for women, $142.8-2,242.4 \mathrm{mg} /$ day in $\mathrm{T} 1,1,450.8-3,441.6 \mathrm{mg} /$ day in $\mathrm{T} 2$, and $2,223.0-13,303.9 \mathrm{mg} /$ day in $\mathrm{T} 3$.

Multinomial logistic regression was performed to identify the link of potassium intake with the risk of osteoporosis and osteopenia, used as ordered outcomes adjusting for putative covariates of bone health. Potential confounders are either known or suspected risk factors for osteoporosis from previous studies $[29,30]$. Multivariate analyses of the multinomial logistic regression were conducted in three models. Model 1 was controlled for age, BMI (continuous), and energy consumption (continuous). Model 2 also included quartile household income, four educational levels, alcohol consumption status (non-current and current), smoking status (never, past, and current), physical activity (inactive, minimally active, health promoting active). Finally, Model 3 was adjusted for serum vitamin D concentration (continuous) and residual energy-adjusted calcium intake 
(continuous). Missing values of continuous variables were replaced by the median and the missing statement of categorical variables was defined as the 'missing' group. All statistical analyses were performed using SAS version 9.4 (SAS Institute Inc., Cary, NC, USA).

\section{RESULTS}

General characteristics of participants according to potassium intake

Mean ages were $61.9 \pm 0.2$ years in men and $62.3 \pm 0.2$ years in women. Mean potassium intakes were $3,258 \pm 38 \mathrm{mg} / \mathrm{d}$ in men and 2,620 $\pm 29 \mathrm{mg} / \mathrm{d}$ in women. The general characteristics of subjects based on potassium tertile levels are described in Table 1. Data were similar for men and women. Subjects in group T3 (highest potassium consumption) were more likely to be younger and at a high level of household income and education, and less likely to be current smokers, compared with those in group T1 (lowest potassium intake). Men in group T3 had a higher BMl and were more health promotingly active than those in group T1. Furthermore, women in the T3 group had greater serum vitamin D levels compared to those in the T1 group. Furthermore, the level of energy and calcium consumption, and energy percentage from protein and fat, was positively associated with potassium intake. In contrast, energy from carbohydrate intake was inversely related to potassium

Table 1. General characteristics of participants according to tertile ${ }^{1)}$ groups of potassium intake

\begin{tabular}{|c|c|c|c|c|c|c|c|c|}
\hline & \multicolumn{4}{|c|}{ Men $(n=3,590)$} & \multicolumn{4}{|c|}{ Women $(n=5,142)$} \\
\hline & $\begin{array}{c}\text { T1 } \\
(\mathrm{n}=1,196)\end{array}$ & $\begin{array}{c}\text { T2 } \\
(n=1,197)\end{array}$ & $\begin{array}{c}\text { T3 } \\
(n=1,197)\end{array}$ & $P$-value ${ }^{2)}$ & $\begin{array}{c}T 1 \\
(n=1,173)\end{array}$ & $\begin{array}{c}\mathrm{T} 2 \\
(\mathrm{n}=1,176)\end{array}$ & $\begin{array}{c}\text { T3 } \\
(n=1,173)\end{array}$ & $P$-value \\
\hline Median potassium intake $(\mathrm{mg} / \mathrm{d})$ & $1,809.1$ & $2,936.2$ & $4,504.2$ & & $1,371.4$ & $2,331.7$ & $3,765.7$ & \\
\hline Age (yrs) & $61.9 \pm 0.3$ & $60.8 \pm 0.3$ & $61.4 \pm 0.3$ & $<0.001$ & $62.5 \pm 0.3$ & $62.1 \pm 0.3$ & $61.8 \pm 0.3$ & $<0.001$ \\
\hline Height (cm) & $166.1 \pm 0.2$ & $167.3 \pm 0.2$ & $167.8 \pm 0.2$ & $<0.001$ & $153.0 \pm 0.2$ & $153.3 \pm 0.2$ & $154.3 \pm 0.2$ & $<0.001$ \\
\hline Weight (kg) & $64.8 \pm 0.4$ & $66.9 \pm 0.4$ & $68.0 \pm 0.4$ & $<0.001$ & $56.6 \pm 0.3$ & $57.3 \pm 0.3$ & $57.6 \pm 0.2$ & $<0.001$ \\
\hline BMl $\left(\mathrm{kg} / \mathrm{m}^{2}\right)$ & $23.5 \pm 0.1$ & $23.9 \pm 0.1$ & $24.1 \pm 0.1$ & 0.001 & $24.2 \pm 0.1$ & $24.4 \pm 0.1$ & $24.2 \pm 0.1$ & 0.160 \\
\hline Serum vitamin $D(\mathrm{ng} / \mathrm{mL})$ & $20.4 \pm 0.3$ & $21.2 \pm 0.3$ & $21.2 \pm 0.3$ & 0.408 & $17.5 \pm 0.3$ & $18.4 \pm 0.3$ & $18.9 \pm 0.2$ & 0.033 \\
\hline \multicolumn{9}{|l|}{ Household income $e^{3)}$} \\
\hline Lowest & $465(33.4)$ & $348(23.7)$ & $295(20.6)$ & $<0.001$ & $727(39.7)$ & $600(31.4)$ & $530(28.0)$ & $<0.001$ \\
\hline Lower middle & $328(28.2)$ & $341(28.8)$ & $272(22.2)$ & & $438(27.1)$ & $434(26.3)$ & $419(25.7)$ & \\
\hline Upper middle & $198(19.2)$ & $239(22.0)$ & $299(25.7)$ & & $295(19.1)$ & $336(22.1)$ & $343(21.2)$ & \\
\hline Highest & $189(19.2)$ & $256(25.5)$ & $322(31.4)$ & & $229(14.1)$ & $317(20.3)$ & $395(25.1)$ & \\
\hline \multicolumn{9}{|l|}{ Educational level } \\
\hline$\leq$ Elementary school & $480(41.0)$ & $393(33.9)$ & $299(27.9)$ & $<0.001$ & $1,041(69.0)$ & $951(61.9)$ & $872(54.1)$ & $<0.001$ \\
\hline Middle school & $220(23.0)$ & $197(19.9)$ & $226(22.1)$ & & $186(13.9)$ & $222(16.3)$ & $233(17.7)$ & \\
\hline High school & $205(22.2)$ & $277(29.4)$ & $285(28.8)$ & & $171(14.3)$ & $214(16.5)$ & $297(21.0)$ & \\
\hline$\geq$ College & 105 (13.4) & $158(16.8)$ & $226(21.2)$ & & $35(2.8)$ & $73(5.3)$ & $105(7.2)$ & \\
\hline \multicolumn{9}{|l|}{ Alcohol consumption } \\
\hline Non-alcohol drinker & $329(26.5)$ & $313(25.1)$ & $285(21.9)$ & 0.091 & $684(41.7)$ & $637(38.6)$ & $720(41.4)$ & 0.307 \\
\hline Current alcohol drinker & $849(73.5)$ & $878(74.9)$ & $906(78.1)$ & & $1,006(58.3)$ & $1,062(61.4)$ & $978(58.6)$ & \\
\hline \multicolumn{9}{|l|}{ Smoking status } \\
\hline Never smoked & $183(15.7)$ & $206(15.9)$ & $216(17.1)$ & 0.046 & $1,510(88.5)$ & $1,568(90.8)$ & $1,594(93.0)$ & 0.012 \\
\hline Past smoker & $242(21.7)$ & $317(26.4)$ & $326(27.7)$ & & $33(2.7)$ & $28(1.9)$ & $27(1.9)$ & \\
\hline Current smoker & $757(62.6)$ & $670(57.7)$ & $651(55.3)$ & & $153(8.8)$ & $105(7.3)$ & $84(5.1)$ & \\
\hline \multicolumn{9}{|l|}{ Physical activity } \\
\hline Inactive & $564(47.4)$ & $486(43.6)$ & $418(38.3)$ & 0.002 & $852(49.4)$ & $816(47.4)$ & $785(45.4)$ & 0.355 \\
\hline Minimally active & $347(29.7)$ & $379(28.9)$ & $394(30.3)$ & & $526(32.1)$ & $556(33.9)$ & $563(33.5)$ & \\
\hline Health promoting active & $269(23.0)$ & $326(27.5)$ & $380(31.4)$ & & $314(18.6)$ & $325(18.7)$ & $353(21.1)$ & \\
\hline \multicolumn{9}{|l|}{ Dietary intake } \\
\hline Energy intake (kcal) & $1,622.0 \pm 18.0$ & $2,110.1 \pm 22.1$ & $2,659.5 \pm 26.3$ & $<0.001$ & $1,160.0 \pm 10.5$ & $1,541.7 \pm 11.8$ & $2,000.4 \pm 19.0$ & $<0.001$ \\
\hline Carbohydrate (\% of $\mathrm{E}$ ) & $74.2 \pm 0.4$ & $69.6 \pm 0.4$ & $67.9 \pm 0.4$ & $<0.001$ & $77.0 \pm 0.3$ & $73.4 \pm 0.3$ & $71.9 \pm 0.3$ & 0.001 \\
\hline Protein (\% of E) & $13.1 \pm 0.1$ & $14.9 \pm 0.1$ & $15.8 \pm 0.2$ & $<0.001$ & $12.0 \pm 0.1$ & $13.5 \pm 0.1$ & $14.2 \pm 0.1$ & $<0.001$ \\
\hline Fat $(\%$ of $E$ ) & $12.8 \pm 0.3$ & $15.5 \pm 0.3$ & $16.2 \pm 0.3$ & $<0.001$ & $11.0 \pm 0.2$ & $13.1 \pm 0.2$ & $13.8 \pm 0.2$ & $<0.001$ \\
\hline Potassium (mg) & $1,860.2 \pm 17.3$ & $3,054.3 \pm 16.6$ & $4,898.5 \pm 51.5$ & $<0.001$ & $1,394.5 \pm 13.2$ & $2,388.1 \pm 14.1$ & $4,157.0 \pm 41.4$ & $<0.001$ \\
\hline Calcium (mg) & $355.3 \pm 9.9$ & $546.0 \pm 11.0$ & $759.2 \pm 12.4$ & $<0.001$ & $265.6 \pm 10.7$ & $410.2 \pm 6.6$ & $612.1 \pm 10.1$ & $<0.001$ \\
\hline
\end{tabular}

Values are presented as mean \pm standard error (SE) for continuous variables and weighted $\mathrm{n}$ (percent) for categorical variables.

1) The ranges of potassium intake for each tertile were as follows: for men, 386.7-2,726.5 mg/day in T1, 1,994.6-3,950.9 mg/day in T2, and 2,935.6-18,573.0 mg/day in T3; for women, 142.8-2,242.4 mg/day in T1, 1,450.8-3,441.6 mg/day in T2, and 2,223.0-13,303.9 mg/day in T3.

2) $P$-values are calculated by survey regression for continuous variables adjusted for age and energy intake, and by chi-square tests for categorical variables.

${ }^{3)}$ Household income was categorized into quartiles according to sex and age group. 
intake among both males and females.

$B M D$ and prevalence of osteoporosis according to potassium intake The BMD value from six bone measurement sites and the distribution of osteopenia and osteoporosis based on potassium intake are presented in Table 2. BMD values of the total femur $(P=0.031)$ and Ward's triangle $(P=0.010)$ were statistically different according to the potassium intake among men. Women in the T3 group had greater BMD at all measurement points (total femur $P=0.013$, trochanter $P=0.033$, intertrochanter $P=0.041$, femoral neck $P=0.025$, Ward's triangle $P=$
0.019 , and lumbar spine $P=0.009$ ) than women in the $\mathrm{T} 1$ group. The osteoporosis prevalence in men was $8.1 \%$ and in women was $25.5 \%$. In the T3 group, the prevalence of osteoporosis at the femoral neck and lumbar spine was significantly lower compared to the T1 group, among both males and females (all $P<0.001$ ).

The association of potassium intake with osteopenia and osteoporosis

The odd ratios (ORs) and 95\% confidence intervals (Cls) for osteopenia and osteoporosis according to potassium intake are presented in Table 3. Using group T1 as the reference group,

Table 2. Bone mineral density and prevalence of osteoporosis and osteopenia according to tertile ${ }^{1)}$ groups of potassium intake

\begin{tabular}{|c|c|c|c|c|}
\hline & \multicolumn{3}{|c|}{ Potassium intake } & \multirow{2}{*}{$P$-value ${ }^{2)}$} \\
\hline & $\mathrm{T} 1$ & $\mathrm{~T} 2$ & T3 & \\
\hline \multicolumn{5}{|l|}{ Men $(n=3,590)$} \\
\hline \multicolumn{5}{|c|}{ Bone mineral density $\left(\mathrm{g} / \mathrm{cm}^{2}\right)^{3)}$} \\
\hline Total femur & $0.903 \pm 0.006$ & $0.930 \pm 0.004$ & $0.941 \pm 0.005$ & 0.031 \\
\hline Trochanter & $0.656 \pm 0.004$ & $0.677 \pm 0.004$ & $0.686 \pm 0.004$ & 0.062 \\
\hline Intertrochanter & $1.084 \pm 0.007$ & $1.114 \pm 0.006$ & $1.127 \pm 0.006$ & 0.060 \\
\hline Femoral neck & $0.728 \pm 0.005$ & $0.755 \pm 0.004$ & $0.767 \pm 0.005$ & 0.157 \\
\hline Ward's triangle & $0.502 \pm 0.005$ & $0.520 \pm 0.005$ & $0.530 \pm 0.005$ & 0.010 \\
\hline Lumbar spine & $0.931 \pm 0.006$ & $0.952 \pm 0.005$ & $0.949 \pm 0.005$ & 0.351 \\
\hline \multicolumn{5}{|l|}{ Prevalence ${ }^{4)}$} \\
\hline \multicolumn{5}{|l|}{ Femoral neck } \\
\hline Normal & $565(53.2)$ & $658(61.9)$ & $716(64.5)$ & $<0.001$ \\
\hline Osteopenia & $552(41.4)$ & $481(34.7)$ & $445(32.7)$ & \\
\hline Osteoporosis & $79(5.4)$ & $58(3.4)$ & $36(2.8)$ & \\
\hline \multicolumn{5}{|l|}{ Lumbar spine } \\
\hline Normal & $597(52.8)$ & $662(60.1)$ & $677(59.2)$ & $<0.001$ \\
\hline Osteopenia & $416(34.5)$ & $407(32.1)$ & $403(33.2)$ & \\
\hline Osteoporosis & $183(12.7)$ & $128(7.8)$ & $117(7.6)$ & \\
\hline \multicolumn{5}{|l|}{ Women $(n=5,142)$} \\
\hline \multicolumn{5}{|c|}{ Bone mineral density $\left(\mathrm{g} / \mathrm{cm}^{2}\right)$} \\
\hline Total femur & $0.768 \pm 0.005$ & $0.784 \pm 0.004$ & $0.796 \pm 0.004$ & 0.013 \\
\hline Trochanter & $0.561 \pm 0.003$ & $0.573 \pm 0.003$ & $0.581 \pm 0.003$ & 0.033 \\
\hline Intertrochanter & $0.931 \pm 0.006$ & $0.949 \pm 0.005$ & $0.962 \pm 0.005$ & 0.041 \\
\hline Femoral neck & $0.620 \pm 0.004$ & $0.635 \pm 0.004$ & $0.646 \pm 0.004$ & 0.025 \\
\hline Ward's triangle & $0.430 \pm 0.005$ & $0.447 \pm 0.005$ & $0.457 \pm 0.004$ & 0.019 \\
\hline Lumbar spine & $0.810 \pm 0.005$ & $0.820 \pm 0.005$ & $0.829 \pm 0.005$ & 0.009 \\
\hline \multicolumn{5}{|l|}{ Prevalence } \\
\hline \multicolumn{5}{|l|}{ Femoral neck } \\
\hline Normal & $377(25.2)$ & $427(27.7)$ & $486(31.1)$ & $<0.001$ \\
\hline Osteopenia & $904(51.3)$ & $922(52.3)$ & $912(51.2)$ & \\
\hline Osteoporosis & $432(23.5)$ & $367(20.0)$ & $315(17.8)$ & \\
\hline \multicolumn{5}{|l|}{ Lumbar spine } \\
\hline Normal & $403(27.9)$ & $436(28.0)$ & $501(31.7)$ & $<0.001$ \\
\hline Osteopenia & $684(39.6)$ & $732(44.0)$ & $701(40.1)$ & \\
\hline Osteoporosis & $626(32.5)$ & $548(28.0)$ & $511(28.2)$ & \\
\hline
\end{tabular}

Values are presented as mean \pm standard error (SE) for continuous variables and weighted $\mathrm{n}$ (percent) for categorical variables.

1) The ranges of potassium intake for each tertile were as follows: for men, 386.7-2,726.5 mg/day in T1, 1,994.6-3,950.9 mg/day in T2, and 2,935.6-18,573.0 mg/day in T3; for women, 142.8-2,242.4 mg/day in T1, 1,450.8-3,441.6 mg/day in T2, and 2,223.0-13,303.9 mg/day in T3.

2) $P$-values were calculated by survey regression for bone mineral density adjusted for age and energy intake, and by chi-square tests for prevalence of osteoporosis and osteopenia.

3) The BMD $\left(\mathrm{g} / \mathrm{cm}^{2}\right)$ was measured at the lumbar spine (L1-L4 spine) and five regions of the femur (total femur, trochanter, intertrochanter, femoral neck, and Ward' $s$ triangle) using dual-energy X-ray absorptiometry (DEXA, Discovery QDR 4500; Hologic, Inc., Waltham, MA, USA) at the health examination site.

4) Normal defined as T-score $\geq-1.0$, osteopenia defined at $-2.5 \leq$ T-score $<-1.0$, and osteoporosis defined at T-score $<-2.5$. 
Table 3. Multivariate adjusted odds ratios and $95 \% \mathrm{Cl}$ for osteopenia and osteoporosis according to tertile ${ }^{1)}$ groups of potassium intake

\begin{tabular}{|c|c|c|c|c|c|c|c|c|}
\hline \multirow{3}{*}{ Potassium intake } & \multicolumn{4}{|c|}{ Osteopenia $^{2)}$} & \multicolumn{4}{|c|}{ Osteoporosis $^{3)}$} \\
\hline & $\mathrm{T} 1$ & $\mathrm{~T} 2$ & T3 & \multirow{2}{*}{$P$ for trend ${ }^{4)}$} & $\mathrm{T} 1$ & $\mathrm{~T} 2$ & T3 & \multirow{2}{*}{$P$ for trend } \\
\hline & Ref & OR $(95 \% \mathrm{Cl})$ & OR $(95 \% \mathrm{Cl})$ & & Ref & OR $(95 \% \mathrm{Cl})$ & OR $(95 \% \mathrm{Cl})$ & \\
\hline \multicolumn{9}{|l|}{ Men $(n=3,590)$} \\
\hline \multicolumn{9}{|l|}{ Femoral neck } \\
\hline Model $1^{5)}$ & 1.00 & $0.81(0.64-1.02)$ & $0.74(0.56-0.98)$ & 0.045 & 1.00 & $0.71(0.43-1.16)$ & $0.59(0.32-1.08)$ & 0.091 \\
\hline Model $2^{6)}$ & 1.00 & $0.84(0.67-1.07)$ & $0.82(0.61-1.10)$ & 0.218 & 1.00 & $0.74(0.45-1.24)$ & $0.72(0.37-1.41)$ & 0.343 \\
\hline Model $3^{7)}$ & 1.00 & $0.91(0.72-1.16)$ & $0.94(0.69-1.28)$ & 0.759 & 1.00 & $0.85(0.51-1.42)$ & $0.89(0.44-1.81)$ & 0.764 \\
\hline \multicolumn{9}{|l|}{ Lumbar spine } \\
\hline Model 1 & 1.00 & $0.93(0.72-1.18)$ & $1.10(0.81-1.50)$ & 0.477 & 1.00 & $0.62(0.45-0.85)$ & $0.63(0.42-0.96)$ & 0.044 \\
\hline Model 2 & 1.00 & $0.97(0.75-1.24)$ & $1.19(0.87-1.63)$ & 0.227 & 1.00 & $0.68(0.49-0.95)$ & $0.79(0.49-1.25)$ & 0.345 \\
\hline Model 3 & 1.00 & $1.00(0.78-1.29)$ & $1.26(0.91-1.76)$ & 0.145 & 1.00 & $0.70(0.50-0.98)$ & $0.82(0.51-1.33)$ & 0.476 \\
\hline \multicolumn{9}{|l|}{ Women $(n=5,142)$} \\
\hline \multicolumn{9}{|l|}{ Femoral neck } \\
\hline Model 1 & 1.00 & $0.91(0.72-1.16)$ & $0.72(0.55-0.94)$ & 0.014 & 1.00 & $0.83(0.59-1.17)$ & $0.68(0.46-1.01)$ & 0.056 \\
\hline Model 2 & 1.00 & $0.95(0.75-1.22)$ & $0.79(0.60-1.04)$ & 0.073 & 1.00 & $0.90(0.64-1.27)$ & $0.78(0.52-1.17)$ & 0.232 \\
\hline Model 3 & 1.00 & $0.97(0.75-1.24)$ & $0.81(0.61-1.07)$ & 0.117 & 1.00 & $0.92(0.65-1.31)$ & $0.81(0.54-1.22)$ & 0.313 \\
\hline \multicolumn{9}{|l|}{ Lumbar spine } \\
\hline Model 1 & 1.00 & $1.09(0.87-1.38)$ & $0.81(0.61-1.07)$ & 0.087 & 1.00 & $0.74(0.57-0.97)$ & $0.52(0.37-0.72)$ & $<0.001$ \\
\hline Model 2 & 1.00 & $1.15(0.91-1.46)$ & $0.89(0.67-1.19)$ & 0.308 & 1.00 & $0.83(0.63-1.09)$ & $0.64(0.46-0.89)$ & 0.009 \\
\hline Model 3 & 1.00 & $1.14(0.90-1.45)$ & $0.87(0.65-1.17)$ & 0.249 & 1.00 & $0.85(0.65-1.12)$ & $0.68(0.48-0.96)$ & 0.030 \\
\hline
\end{tabular}

1) The ranges of potassium intake for each tertile were as follows: for men, 386.7-2,726.5 mg/day in T1, 1,994.6-3,950.9 mg/day in T2, and 2,935.6-18,573.0 mg/day in T3; for women, 142.8-2,242.4 mg/day in T1, 1,450.8-3,441.6 mg/day in T2, and 2,223.0-13,303.9 mg/day in T3.

2) Osteopenia defined as $-2.5 \leq$ T-score $<-1.0$.

3) Osteoporosis defined as T-score $<-2.5$.

4) Linear trends across categories of potassium intake were tested using the median intake value for each category as an ordinal variable

${ }^{5)}$ Model 1 adjusted for age (continuous), BMl (continuous), and energy intake (continuous).

6) Model 2 adjusted as for Model 1 + smoking status (never smoker, past smoker, and current smoker), alcohol consumption (non-current drinker and current drinker), physical activity (yes and no), educational level ( $\leq$ elementary school, middle school, high school, or $\geq$ college), and household income (lowest, lower middle, upper middle, and highest).

${ }^{7)}$ Model 3 adjusted as for Model $2+$ serum vitamin D and calcium intake (energy adjusted by residual method).

men in T3 were associated with decreased odds for osteoporosis at the lumbar spine in model 1, controlled for age, BMl, and energy intake (OR: $0.63,95 \% \mathrm{Cl}: 0.42-0.96, P$ trend $=0.044$ ). However, this association was attenuated in model 3, which also adjusted for smoking status, alcohol consumption, physical activity, education, household income, serum vitamin D, and energy-adjusted calcium intake (OR: $0.82,95 \% \mathrm{Cl}$ : $0.51-1.33, P$ trend $=0.476$ ). The women in the T3 group showed a decreased OR for osteoporosis in the lumbar spine (OR: $0.68,95 \% \mathrm{Cl}$ : $0.48-0.96, P$ trend $=0.030$ ) in fully adjusted model 3 . However, potassium intake level was not statistically associated with the odds for osteoporosis among men.

\section{DISCUSSION}

The crucial finding in this study is the positive link of dietary potassium with bone health among Korean older adults, particularly in females. After adjusting for the putative confounders, the osteoporosis prevalence at the lumbar spine was $32 \%$ lower in women with a higher potassium intake than in those with a lower intake. However, this association was not significant among men.

Our findings are further supported by the evidence from previous epidemiological studies [10,30-34]. The EPIC-Norfolk cohort study reported positive association of dietary potassium intake with a quantitative ultrasound measurement of bone density status and reduced fracture risk of a population in the United Kingdom [30]. Another study in a similar age group identified that higher dietary potassium is associated with an increase in total hip and femur neck BMD in both males and females [10]. Furthermore, dietary potassium level was significantly correlated with an increased BMD in total body and lumbar spine among men aged 39 to 42 years [33]. It has been reported that greater baseline potassium intake is closely linked to preventing bone mass loss of the femoral neck and trochanter at a 4-year follow-up survey among men [34].

The putative theoretical mechanism of the favorable impact of dietary potassium on bone mechanism is based on the acid-base balance hypothesis [34]. In 1968, Wachman and Bernstein [13] suggested that bone mineral functions as a buffer base, and that lifetime buffering of the acid load from ingestion of mixed diets leads to gradual and accumulated bone loss. They suggested that "The therapy of osteoporosis may lie in its prevention $\cdots$ it might be worthwhile to consider decreasing the rate of bone attrition by the use of a diet favoring 'alkaline ash'. This type of diet would emphasize the ingestion of fruit, vegetables, vegetable protein, and moderate amount of milk." Two nutrients that may have such buffering effects are potassium and magnesium, which are found in a variety of whole, unrefined foods, including fruit and vegetables $[35,36]$. 
Diets high in fruit and vegetables produce more alkaline urine by contributing a variety of compounds which, during their metabolism, accept hydrogen ions [13,36]. In summary, potassium or alkaline potassium salts from fruits and vegetables might protect against bone resorption via $\mathrm{pH}$ homeostasis. Furthermore, potassium treatment raises calcium retention in renal tissue, while a low dietary potassium level increases calcium secretion in the kidneys [37]. A further study of 18 postmenopausal women showed that supplementation with potassium bicarbonate neutralized the status of endogenous acid loads. Additionally, potassium bicarbonate improved calcium equilibrium and blood osteocalcin levels, and reduced hydroxyproline secretion in the urine [38].

In our study, we did not find any significant link between potassium intake and the odds for osteoporosis in men. This disparity may be due to the differing degree of completion of a single day 24-hour dietary recall between men and women. Generally, women in Korea prepare the meals and are more knowledgeable about the dietary contents of food, which may lead to more reliable data collection from women. Furthermore, it is possible that residual confounding effects such as smoking and drinking may have had a greater influence on the null associations in men compared to women.

The current study had some limitations. Firstly, the results cannot be used to determine causality between potassium level and osteoporosis owing to the cross-sectional nature of the study. Hence, longitudinal studies are required to establish causality. Secondly, dietary potassium intake was evaluated via a one day 24-hour recall method, which might not correspond to participant's usual intake. Generally, the Food Frequency Questionnaire (FFQ) or multiple-day 24-hour dietary recall is used to assess usual intake. However, the FFQ had not been validated in the 2008-2011 KNHANES study, so the one-day 24-hour dietary recall method was used. Lastly, we could not exclude the possibility of potential confounding variables (e.g., calcium or vitamin D supplementation, biochemical markers regarding bone metabolism), even if we carefully adjusted for the relevant confounders. Despite these limitations, this is the first study to identify the association of dietary potassium intake with the prevalence of osteopenia and osteoporosis in the older adult Korean population.

In conclusion, our results, based on a representative population in Korea demonstrate that a higher dietary potassium level is positively associated with increased BMD and a decreased risk for osteoporosis in older Korean women. The current study highlights the potential benefits of potassium consumption on bone health among Korean adults. Importantly, we suggest that further prospective studies with a more exact dietary assessment method are needed to verify the link between dietary potassium consumption level and bone health.

\section{CONFLICT OF INTEREST}

The authors declare no conflicts of interest.

\section{ORCID}

Jinwoo Ha: https://orcid.org/0000-0003-0803-8196
Seong-Ah Kim: https://orcid.org/0000-0003-4220-8072

Kyungjoon Lim: https://orcid.org/0000-0002-0300-6550

Sangah Shin: https://orcid.org/0000-0003-0094-1014

\section{REFERENCES}

1. Glaser DL, Kaplan FS. Osteoporosis. Definition and clinical presentation. Spine (Phila Pa 1976) 1997;22:12S-16S.

2. Zhu K, Devine A, Prince RL. The effects of high potassium consumption on bone mineral density in a prospective cohort study of elderly postmenopausal women. Osteoporos Int 2009;20:335-40.

3. Rachner TD, Khosla S, Hofbauer LC. Osteoporosis: now and the future. Lancet 2011;377:1276-87.

4. Park EJ, Joo IW, Jang MJ, Kim YT, Oh K, Oh HJ. Prevalence of osteoporosis in the Korean population based on Korea National Health and Nutrition Examination Survey (KNHANES), 2008-2011. Yonsei Med J 2014;55:1049-57.

5. Lim S. Eating a balanced diet: a healthy life through a balanced diet in the age of longevity. J Obes Metab Syndr 2018;27:39-45.

6. Cosman F, de Beur SJ, LeBoff MS, Lewiecki EM, Tanner B, Randall S, Lindsay R; National Osteoporosis Foundation. Clinician's guide to prevention and treatment of osteoporosis. Osteoporos Int 2014;25:2359-81.

7. Dawson-Hughes B, Dallal GE, Krall EA, Harris S, Sokoll L, Falconer G. Effect of vitamin D supplementation on wintertime and overall bone loss in healthy postmenopausal women. Ann Intern Med 1991;115:505-12.

8. Heaney RP. Nutritional factors in osteoporosis. Annu Rev Nutr 1993;13:287-316.

9. New SA, Bolton-Smith C, Grubb DA, Reid DM. Nutritional influences on bone mineral density: a cross-sectional study in premenopausal women. Am J Clin Nutr 1997;65:1831-9.

10. Kong SH, Kim JH, Hong AR, Lee JH, Kim SW, Shin CS. Dietary potassium intake is beneficial to bone health in a low calcium intake population: the Korean National Health and Nutrition Examination Survey (KNHANES) (2008-2011). Osteoporos Int 2017;28:1577-85.

11. Barzel US. The skeleton as an ion exchange system: implications for the role of acid-base imbalance in the genesis of osteoporosis. J Bone Miner Res 1995;10:1431-6.

12. Hamm LL, Nakhoul N, Hering-Smith KS. Acid-base homeostasis. Clin J Am Soc Nephrol 2015;10:2232-42.

13. Wachman A, Bernstein DS. Diet and osteoporosis. Lancet 1968; 1:958-9.

14. Barzel US, Massey LK. Excess dietary protein can adversely affect bone. J Nutr 1998;128:1051-3.

15. Bushinsky DA, Riordon DR, Chan JS, Krieger NS. Decreased potassium stimulates bone resorption. Am J Physiol 1997;272: F774-80.

16. Dawson-Hughes B, Harris SS, Palermo NJ, Castaneda-Sceppa C, Rasmussen HM, Dallal GE. Treatment with potassium bicarbonate lowers calcium excretion and bone resorption in older men and women. J Clin Endocrinol Metab 2009;94:96-102.

17. Sebastian A, Harris ST, Ottaway JH, Todd KM, Morris RC Jr. Improved mineral balance and skeletal metabolism in postmenopausal women treated with potassium bicarbonate. $\mathrm{N}$ Engl J Med 1994;330:1776-81.

18. Lemann J Jr, Gray RW, Pleuss JA. Potassium bicarbonate, but not sodium bicarbonate, reduces urinary calcium excretion and 
improves calcium balance in healthy men. Kidney Int 1989;35: 688-95.

19. Sakhaee K, Nicar M, Hill K, Pak CY, Sakhaee K. Contrasting effects of potassium citrate and sodium citrate therapies on urinary chemistries and crystallization of stone-forming salts. Kidney Int 1983;24:348-52.

20. Weaver CM. Potassium and health. Adv Nutr 2013;4:368S-77S.

21. Lewiecki EM, Gordon CM, Baim S, Leonard MB, Bishop NJ, Bianchi ML, Kalkwarf HJ, Langman CB, Plotkin H, Rauch F, Zemel BS, Binkley $\mathrm{N}$, Bilezikian JP, Kendler DL, Hans DB, Silverman S. International Society for Clinical Densitometry 2007 adult and pediatric official positions. Bone 2008;43:1115-21.

22. Kweon S, Kim Y, Jang MJ, Kim Y, Kim K, Choi S, Chun C, Khang $\mathrm{YH}$, Oh K. Data resource profile: the Korea National Health and Nutrition Examination Survey (KNHANES). Int J Epidemiol 2014;43: 69-77.

23. Rural Development Administration (KO). Food Composition Table. Suwon: Rural Development Administration; 2006.

24. Willet W. Nutritional Epidemiology. New York (NY): Oxford University Press; 2012.

25. Orimo $H$, Hayashi $Y$, Fukunaga $M$, Sone $T$, Fujiwara $S$, Shiraki $M$, Kushida K, Miyamoto S, Soen S, Nishimura J, Oh-Hashi Y, Hosoi T, Gorai I, Tanaka H, Igai T, Kishimoto H; Osteoporosis Diagnostic Criteria Review Committee: Japanese Society for Bone and Mineral Research. Diagnostic criteria for primary osteoporosis: year 2000 revision. J Bone Miner Metab 2001;19:331-7.

26. Yeom HA, Jung D, Choi M. Adherence to physical activity among older adults using a Geographic Information System: Korean National Health and Nutrition Examinations Survey IV. Asian Nurs Res (Korean Soc Nurs Sci) 2011;5:118-27.

27. Ainsworth BE, Haskell WL, Whitt MC, Irwin ML, Swartz AM, Strath SJ, O'Brien WL, Bassett DR Jr, Schmitz KH, Emplaincourt PO, Jacobs DR Jr, Leon AS. Compendium of physical activities: an update of activity codes and MET intensities. Med Sci Sports Exerc 2000;32: S498-504.

28. IPAQ Group. Guidelines for data processing and analysis of the
International Physical Activity Questionnaire [Internet]. [place unknown]: IPAQ Group; 2018 [cited 2018 September 21]. Available from: http://www.ipaq.ki.se.

29. Shin S, Joung H. A dairy and fruit dietary pattern is associated with a reduced likelihood of osteoporosis in Korean postmenopausal women. Br J Nutr 2013;110:1926-33.

30. Hayhoe RP, Lentjes MA, Luben RN, Khaw KT, Welch AA. Dietary magnesium and potassium intakes and circulating magnesium are associated with heel bone ultrasound attenuation and osteoporotic fracture risk in the EPIC-Norfolk cohort study. Am J Clin Nutr 2015;102:376-84.

31. Dawson-Hughes B, Harris SS, Palermo NJ, Gilhooly CH, Shea MK, Fielding RA, Ceglia L. Potassium bicarbonate supplementation lowers bone turnover and calcium excretion in older men and women: a randomized dose-finding trial. J Bone Miner Res 2015;30:2103-11.

32. Gregory NS, Kumar R, Stein EM, Alexander E, Christos P, Bockman RS, Rodman JS. Potassium citrate decreases bone resorption in postmenopausal women with osteopenia: a randomized, doubleblind clinical trial. Endocr Pract 2015;21:1380-6.

33. Whiting SJ, Boyle JL, Thompson A, Mirwald RL, Faulkner RA. Dietary protein, phosphorus and potassium are beneficial to bone mineral density in adult men consuming adequate dietary calcium. J Am Coll Nutr 2002;21:402-9.

34. Tucker KL, Hannan MT, Kiel DP. The acid-base hypothesis: diet and bone in the Framingham Osteoporosis Study. Eur J Nutr 2001;40: 231-7.

35. Chan JC. Nutrition and acid-base metabolism. Fed Proc 1981;40: 2423-8.

36. Remer T, Manz F. Potential renal acid load of foods and its influence on urine pH. J Am Diet Assoc 1995;95:791-7.

37. Lemann J Jr, Pleuss JA, Gray RW. Potassium causes calcium retention in healthy adults. J Nutr 1993;123:1623-6.

38. Sebastian A, Morris RC Jr. Improved mineral balance and skeletal metabolism in postmenopausal women treated with potassium bicarbonate. N Engl J Med 1994;331:279. 